\title{
Experimental Study on Stress Sensitivity Considering Time Effect for Tight Gas Reservoirs
}

\author{
Xiangrong NIE*, Junbin CHEN**, Shaomin YUAN*** \\ *College of Petroleum Engineering, Xi'an Shiyou University, Xi'an, 710065, China, E-mail: nxrcup@163.com \\ **Shaanxi Key Laboratory of Well Stability and Fluid \& Rock Mechanics in Oil and Gas Reservoirs, Xi'an Shiyou \\ University, Xi'an, 710065, China, E-mail: chenjbxu@126.com \\ ***Exploration and Development Research Institute of Daqing Oil Field, Daqing, 163712, China, \\ E-mail: smyuan@sina.com.cn
}

crossref http://dx.doi.org/10.5755/j01.mech.24.6.22462

\section{Introduction}

With the continuous development of petroleum industry, tight oil and gas reservoirs will occupy an increasingly important position in the oil and gas resource strategy. The seepage characteristic is the key research content of tight reservoir. During the drilling and development process, the formation pressure changes and the seepage characteristics of the reservoir rock also change correspondingly. The effective stress is gradually increasing with formation fluid production, which led to reservoir deformation, and porosity and permeability decrease. This phenomenon is called stress sensitivity, which would produce negative impact on oil and gas field exploration [1-5]. Therefore, a number of scientists had regarded stress sensitivity as an important research subject.

In order to correctly evaluate the stress sensitivity of reservoir, a lot of researches have been carried out. Usually, the stress sensitivity experiments of clean sandstone and shale were conducted by increasing confining pressure at first and decreasing later [6-9]. The results show that the permeability is decreasing with confining pressure increasing. When the confining pressure decreased, the sandstone samples had different permeability recovery. The permeability of clean sandstone can recover to $96 \%$ of initial permeability. The permeability of shale can recover to $40 \%$ of initial permeability. It shows that the loss of permeability cannot be entirely eliminated caused by effective stress changed. The elastic deformation and plastic deformation exist at the same time [10]. The study showed that the permeability has a significant change with the stress changed, and cannot be ignored. The stress sensitivity of porosity is weak, and can be ignored [11-14]. For tight gas reservoirs, the stress sensitivity is very serious. The ratio of permeability loss reaches to $90 \%$, which cannot ignore [15]. Through theoretical analysis, it is concluded that the pore pressure decreasing can lead to the effective stress of the rock increasing, resulting in the compression of the pore space and the decrease of pore space, which eventually leads to permeability decreasing [16]. The fracture is the key factor affecting the stress sensitivity of rock. Due to the existence of fracture, the stress sensitivity varies with the loading rounds [17]. Jones et al. proposed to define the stress sensitivity of rock by the ratio of the change of permeability to the change of stress [18]. Scanning electron microscope (SEM) images show that the change of throat shapes and throat size have a big impact on permeability [19]. The exploitation speed of reservoir with stress sensitivity below the reservoir without stress sensitivity, but the stress sensitivity of permeability have nothing to do with ultimate recovery [20].

Accurate evaluation of stress sensitivity is an unusual job, but it has taken a great deal of research to work out how to successfully test different types of rock and different pressure conditions. However, the previous studies had not considered the time impact on stress sensitivity. As we know, the rock exist creep, which is the deformation of rock increasing slowly with time under constant load [21-24]. So, this paper presents experimental study on stress sensitivity considering time effect for tight gas reservoirs.

\section{Stress sensitivity}

The stress sensitivity of reservoir is physical parameters varying with stress including permeability and porosity. The reservoir rock has to bear the gravity of the overlying strata and the fluid pressure in the pore at the same time. In the production process, the overburden pressure $P_{e}$ is considered as a constant in general. The initial reservoir pressure $P_{i}$ decreases to a specific value $P$ with fluid constantly producing. The rock framework and pore are compressed, which lead to the permeability changed. The sketch of stress sensitivity is shown in Fig. 1.

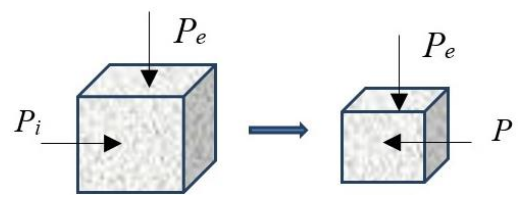

Fig. 1 Sketch of rock stress sensitivity during production

Considering the permeability stress sensitivity, the permeability damage rate can be expressed as:

$$
D=\frac{K_{i}-K}{K_{i}} 100 \%,
$$

where: $D$ is permeability damage rate; $K_{i}$ is the permeability at the first pressure $P_{i}$ in the experiment; $K$ is the permeability at a certain pressure $P$ in the experiment.

\subsection{Instantaneous stress sensitivity (ISS)}

The conventional evaluation methodology of stress sensitivity holds that the rock framework has completed the deformation in a short time. So, the compression time of core in the stress sensitivity experiment was set to 30 minutes based on oil and gas industry standard. However, 
during the study on the stress sensitivity of tight gas reservoir, the deformation of rock framework cannot complete in such a short time (about 30 minutes) was found in many rock creep experiments.

Creep is as a reflection of time effect for rock, and the influence of rock mass engineering is not negligible. The development of rock creep is related to rock type, stress state of rock mass, stress history, stress path, temperature, moisture content and pore water pressure. The typical creep strain and time curves are shown in Fig. 2. When the stress intensity ratio is lower than a certain threshold, the rock strain - time curve is shown in curve 1 . When the stress intensity ratio is far greater than the threshold value, the rock strain - time curve is shown in curve 3 . In addition to these two conditions, rock under the action of constant stress, as well as general rheological materials, strain - time curve consists of three parts: the initial stage, stable stage and accelerating stage, such as curve shown in curve 2 .

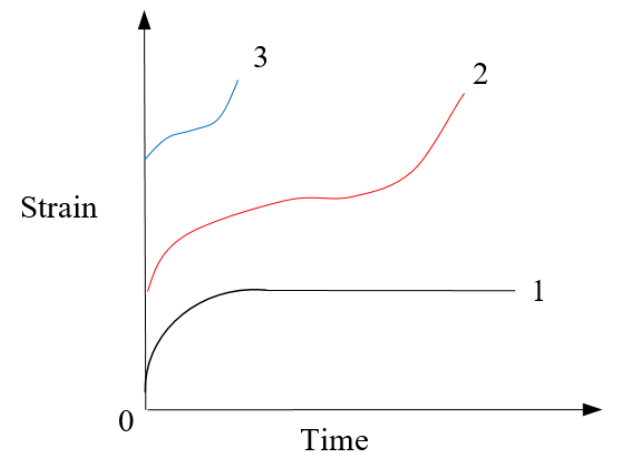

Fig. 2 Curves of creep strain to time of rock

The essence of rock creep is the movement change of microstructure under constant stress, including the diffusion of lattice defects, the opening of cracks and the deformation of grain. That is, the rock framework can continue deformation as time goes on. So, the conventional evaluation methodology is called ISS in this paper. The sketch of ISS is shown in Fig. 3.

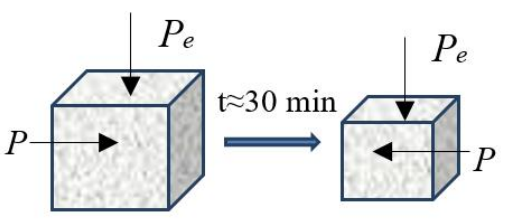

Fig. 3 Sketch of ISS

\subsection{Delayed stress sensitivity (DSS)}

In the same overburden stress and reservoir pressure, the rock framework and pore are compressed continuously as time goes on, which means that the stress sensitivity is related to time. This is the manifestation of rock creep.

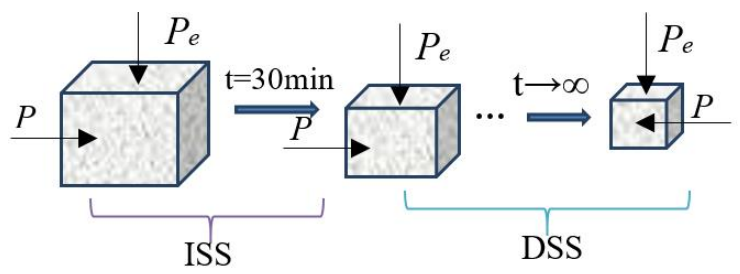

Fig. 4 Sketch of DSS
The creep causes the deterioration of the mechanical properties of rock, which belongs to the category of damage. Damage is generally understood from three perspectives: microscopic, micro and macro. In this paper, the continuous stress sensitivity is called DSS. The sketch of DSS is shown in Fig. 4.

\section{Experimental section}

\subsection{Core sample}

The core samples were from Ordos basin, which are shown in Fig. 5. The core samples were from lower Shihezi formation. The samples were dark grey. The samples are very compact and homogeneous. Field-emission scanning electron microscope (FESEM) and nanometer computed tomography (NCT) were employed to characterize micro pore structure. The nanoscale pores throat are widely developed in the tight reservoir. The main pore types are secondary solution pores and intergranular micropore and little primary pores. In order to meet the experiments demands, the core samples were processed into short cores. For one core, the mineral components are analyzed by $\mathrm{X}$ ray diffraction (XRD). The test results are shown in Fig.6. The clay minerals content was $49.1 \%$.

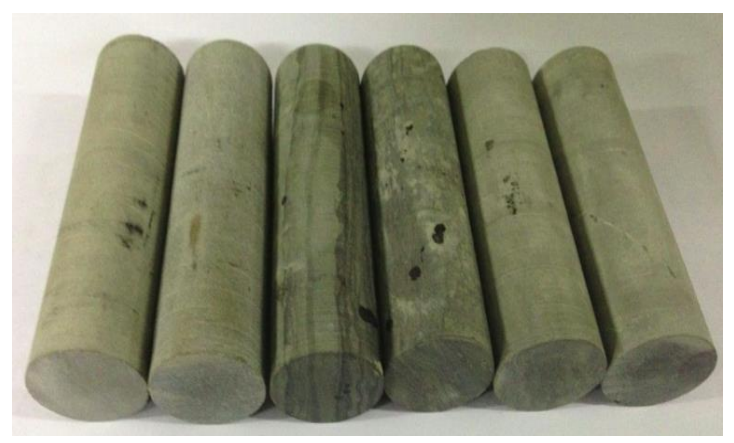

Fig. 5 Experimental samples

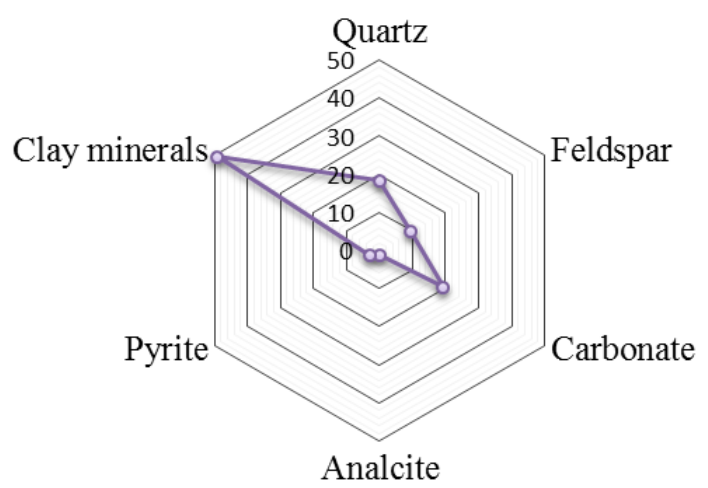

Fig. 6 Mineralogical contents of core sample (\%)

\subsection{Experimental setup}

The experimental setup consists mainly of the following devices: 1. A high pressure stainless-steel gas cell $\left(0-70 \mathrm{MPa} ; \leq 150{ }^{\circ} \mathrm{C} ; 1000 \mathrm{~mL}\right)$ was used to store and deliver gas. 2. A core holder $\left(0-100 \mathrm{MPa} ; \leq 150{ }^{\circ} \mathrm{C}\right)$ was used to realize the core which can be compressed same as reservoir conditions. 3. A confining pressure pump was used to maintain the pre-specified pressure inside the cell during the tests (pressure 0-40 MPa; pressure accuracy, 0.1\%). Several major actual photos of device are shown as Fig. 7. 
Pressure gauge

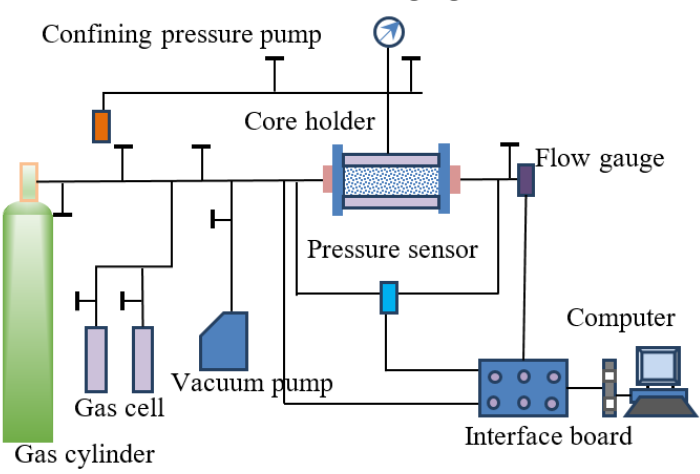

Fig. 7 Schematic of the experimental setup
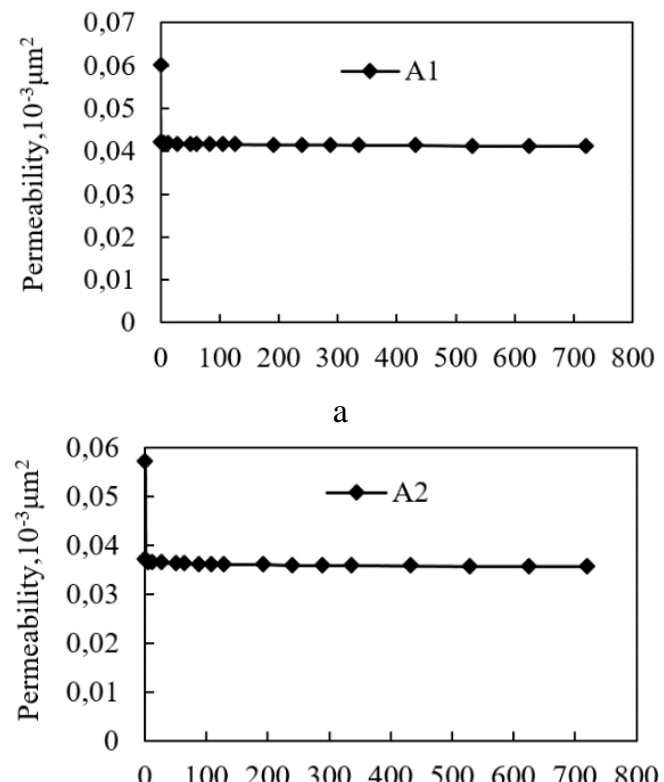

$\mathrm{b}$
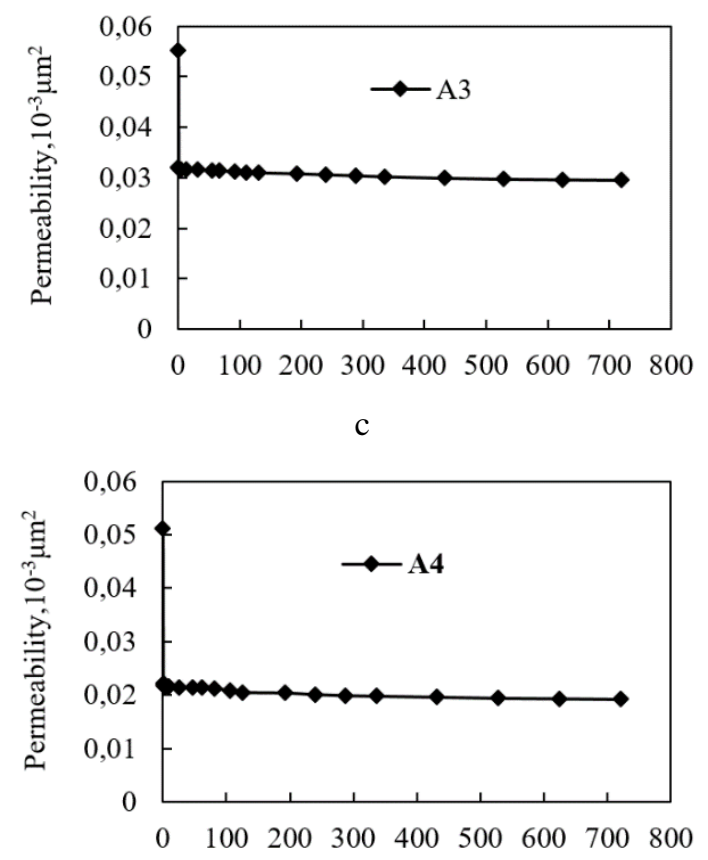

d

Fig. 8 The relation curves between permeability and load time of effective stress

\subsection{Experimental procedures}

In order to study the stress sensitivity of permeability in the tight gas reservoir exploitation process, the rock framework's effective stress $\sigma$ should be calculated. In the research block, the overburden pressure $P_{e}$ is $63.31 \mathrm{MPa}$, and the initial reservoir pressure $P_{i}$ is $24.17 \mathrm{MPa}$. The rock framework's effective stress can be obtained as follows: $\sigma=63.31-24.17=39.14 \mathrm{MPa}$. The experiments were performed by the following procedures: 1 . First, four short cores using in tests were from the full size cores. The two end surfaces should smooth. The benzene and alcohol (1:4) were used to clean the cores last about five to seven days, and then the cores were dried in an incubator under $90^{\circ} \mathrm{C}$ last six hours. 2. The flowing pressure $P_{f}$ was kept constant at $0.53 \mathrm{MPa}$ to test the permeability. Different effective stresses were pre-set for different cores. The effective stress was changed by confining pressure $P_{c}$ varied. The properties and stress conditions of short cores used in experiments are shown in Table 1 . The porosity and permeability are expressed as $\varphi$ and $K$ respectively. 3. The confining pressure was set based on Table 1 for every core. The permeability was tested and recorded every once in a while.

Table 1

Properties and stress conditions of cores sample

\begin{tabular}{|c|c|c|c|c|c|}
\hline NO. & $\begin{array}{c}\varphi, \\
\%\end{array}$ & $\begin{array}{c}K, \\
10^{-3} \mathrm{\mu m}^{2}\end{array}$ & $\begin{array}{c}P_{f}, \\
\mathrm{MPa}\end{array}$ & $\begin{array}{c}P_{c}, \\
\mathrm{MPa}\end{array}$ & $\begin{array}{c}\sigma, \\
\mathrm{MPa}\end{array}$ \\
\hline $\mathrm{A} 1$ & 6.94 & 0.0601 & 0.53 & 10.53 & 10 \\
\hline $\mathrm{A} 2$ & 6.81 & 0.0571 & 0.53 & 20.53 & 20 \\
\hline $\mathrm{A} 3$ & 6.56 & 0.0552 & 0.53 & 40.53 & 40 \\
\hline $\mathrm{A} 4$ & 5.42 & 0.0512 & 0.53 & 45.53 & 45 \\
\hline
\end{tabular}

\subsection{Experimental results}

Based on the above experimental procedures, the cores is tested. The curves of permeability with time were obtained at different rock framework's effective stress, shown in Fig. 8.

\section{Discussion}

Take a core (A4) as an example, the relation curve between permeability and load time of effective stress was shown in Fig.8. The permeability falls from $0.0512 \times 10^{-3} \mu \mathrm{m}^{2}$ to $0.0221 \times 10^{-3} \mu \mathrm{m}^{2}$ within half an hour rapidly, named as ISS. From $0.5 \mathrm{~h}$ to $720 \mathrm{~h}$, the permeability falls from $0.0221 \times 10^{-3} \mu \mathrm{m}^{2}$ to $0.0192 \times 10^{-3} \mu \mathrm{m}^{2}$ rapidly, called as DSS. It is evident from Fig. 9 that the permeability was still falling as time passed.

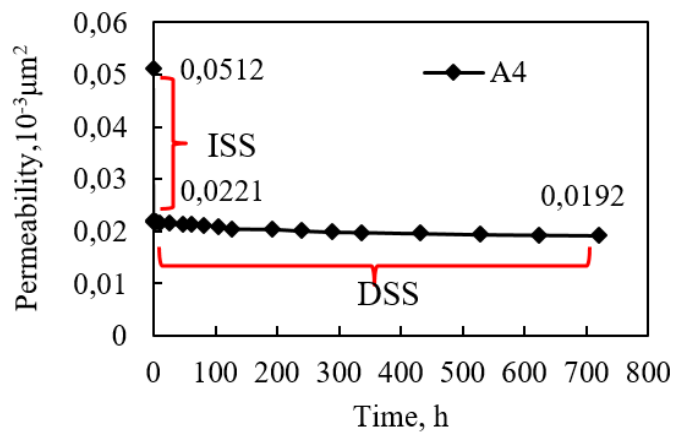

Fig. 9 The relation between ISS and DSS 
After further analysis the data of DSS, the descending rates of permeability are different during different time periods. As shown in Figs. 10 - 13, the permeability can be divided into two distinct phases. In the first 100 hours, the permeability decreased greatly, and after more than 100 hours, the rate of permeability changed gradually.

By analyse the experiment results, it shows that the stress sensitivity of permeability is time-related. More precisely, the permeability of core samples decreased continuously with the prolonging of pressurization time. With the increase of pressurization time, the permeability decrease rates gradually reduced. The value of permeability decreases rapidly within 30 minutes. The permeability and time fitted linear relation. About 100 hours later, the permeability and time fitted exponential equation. Through analysis of the experiment results, it shows that the closure of pore throat is an evolutionary process, caused by creep properties.

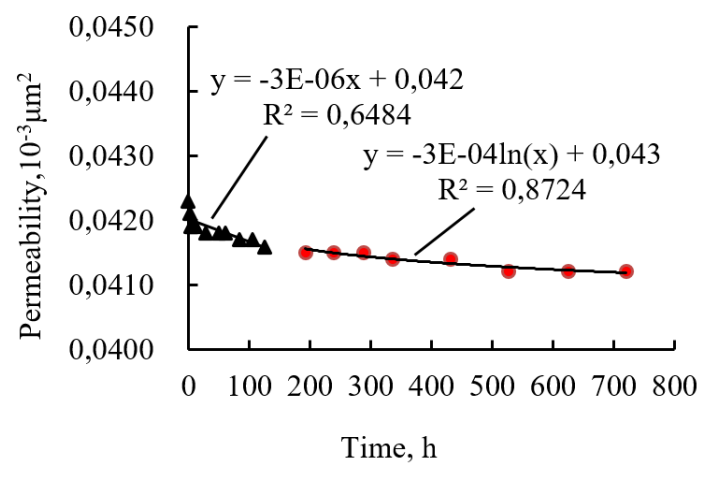

Fig. 10 Fitting curves of DSS (A1)

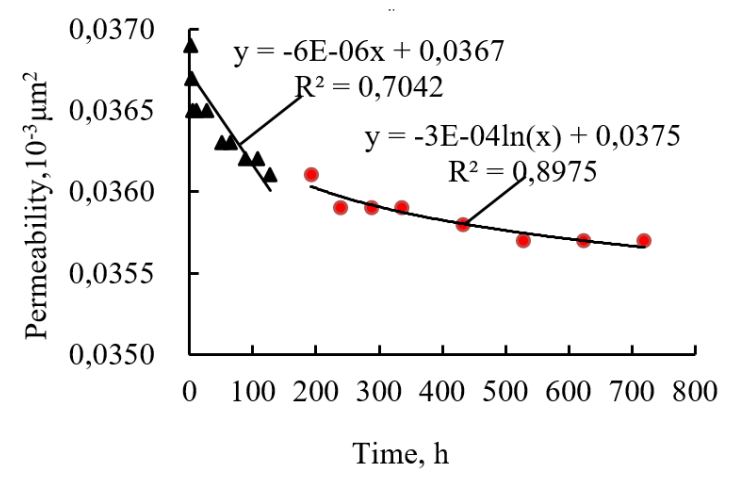

Fig. 11 Fitting curves of DSS (A2)

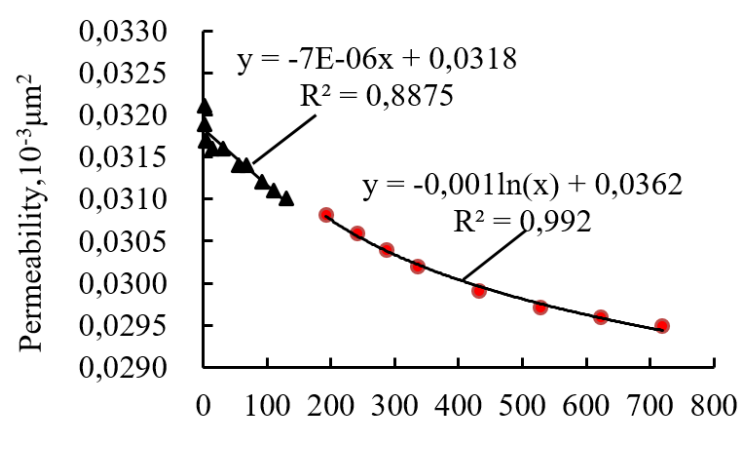

Time, $\mathrm{h}$

Fig. 12 Fitting curves of DSS (A3)

By fitting the permeability and time, two functions were obtained to describe the relationship between permeability $K$ and time. Combining with the ISS, the stress sensitivity of permeability considering time effect is shown in Table 2.

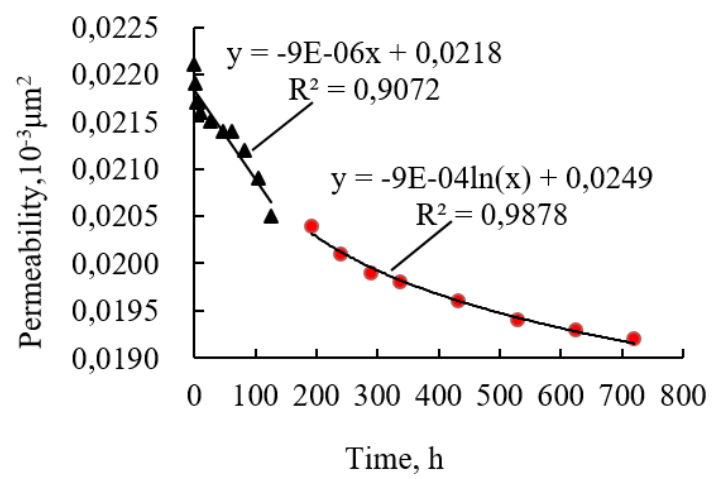

Fig. 13 Fitting curves of DSS (A4)

Table 2

Fitting results of permeability stress sensitivity

\begin{tabular}{|c|c|c|c|}
\hline \multirow{2}{*}{ NO. } & \multicolumn{3}{|c|}{$K, 10^{-3} \mu \mathrm{m}^{2}$} \\
\cline { 2 - 4 } & $t=0.5 \mathrm{~h}$ & $t_{1} \leq t \leq t_{2}$ & $t_{2} \leq t$ \\
\hline A1 & $K=0.0423$ & $K=-3 \times 10^{-6} t+0.042$ & $K=0.0417 \mathrm{e}^{-0.00002 t}$ \\
\hline A2 & $K=0.0371$ & $K=-6 \times 10^{-6} t+0.0367$ & $K=0.0361 \mathrm{e}^{-0.00002 t}$ \\
\hline A3 & $K=0.0321$ & $K=-7 \times 10^{-6} t+0.0318$ & $K=0.0311 \mathrm{e}^{-0.00008 t}$ \\
\hline A4 & $K=0.0221$ & $K=-9 \times 10^{-6} t+0.0218$ & $K=0.0206 \mathrm{e}^{-0.0001 t}$ \\
\hline
\end{tabular}

The damage rate of permeability $D_{\mathrm{t}}$ was quantitative described the level of damage of stress sensitivity on permeability, as shown in Eq. (2).

$$
D_{t}=\frac{K_{i}-K(t)}{K_{i}} 100 \% \text {; }
$$

Based on Eq. 2, the results were shown in Fig. 14. The damage rate of permeability is no longer a fixed value, but changes as time. It indicates that the conventional evaluation method of permeability damage rate is not accurate. The conventional evaluation method underestimated the damage degree of stress sensitivity to reservoir. Therefore, it is necessary to promote the new method in this paper.

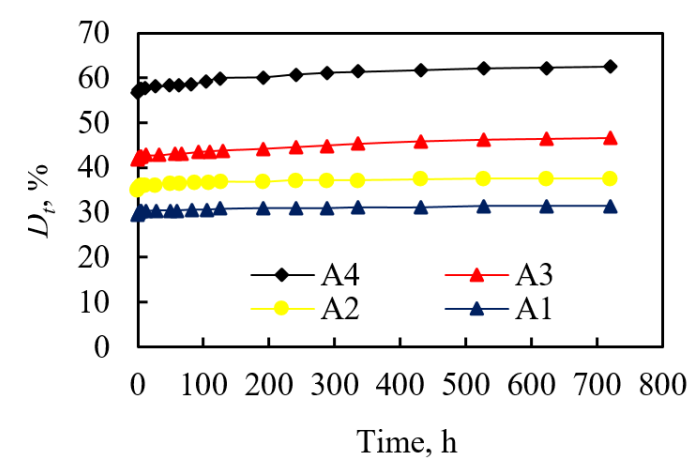

Fig. 14 The relation curves between damage rate of permeability and time

As seen in Fig. 15, it shows the morphology of different clay minerals. By the X-ray, the average clay mineral content of the four cores was $49.1 \%$. The Previous studies have shown that the content of different minerals in rock is the main factor controlling its mechanical properties, and the content of quartz is positively correlated with Young's modulus. The clay minerals were also positively correlated 
with Poisson's ratio. The brittle minerals can improve the rigidity of rocks, while clay minerals have strong creep properties. This is the reason why DSS appears in tight sandstone.
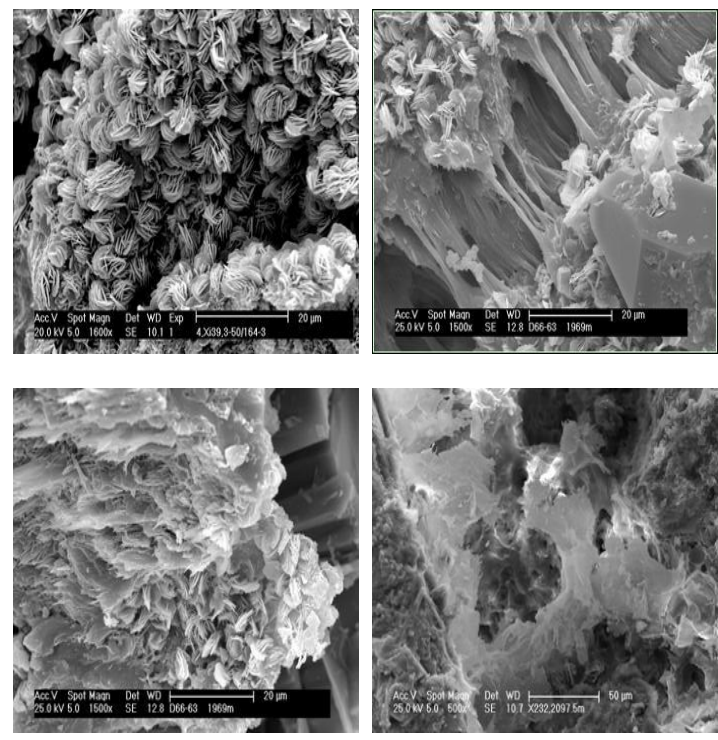

Fig. 15 SEM images of clay minerals

\section{Conclusions}

Experimental studies were performed to investigate the stress sensitivity considering time effect for tight gas reservoirs. As a result of our experiments, conclusions can be drawn as follows:

1. For tight gas reservoir, the pressure declines, and effective stress increase correspondingly, which could cause pore throat close. Though the tests in this paper, it shows that the pore is a process of gradual closure, which led the permeability decreases gradually as time passed.

2. In this paper, a new stress sensitivity evaluation method for tight reservoir is presented considering time effect. The stress sensitivity for tight reservoir is divided into two phases on time scale, which are ISS and DSS respectively.

3. When evaluated stress sensitivity for tight reservoir level, the load time of stress effective should continue until delayed stress sensitivity comes.

\section{Acknowledgements}

This research was funded by National Natural Science Foundation of China (51674197, 51874239), Scientific Research Program Funded by Shaanxi Provincial Education Department (18JK0628), and Natural Science Basic Research Plan in Shaanxi Province of China (2018JQ4033).

\section{References}

1. Yang, Z.; Yang, H.; Chen, H.; Zhang, H. 2017. New method for evaluating rock stress sensitivity for low-permeability tight gas reservoirs, Chemistry \& Technology of Fuels \& Oils 53(1):68-76. http://dx.doi.org/ 10.1007/s10553-017-0782-x.

2. Zhao, F.; Tang, H.; Meng, Y.; Li, G.; Xing, X. 2009. Damage evaluation for water-based underbalanced drill- ing in low-permeability and tight sandstone gas reservoirs, Petroleum Exploration \& Development 36(1):113-119. https://doi.org/10.1016/S1876-3804(09)60114-2.

3. Wang, D.; Ge, H.; Wang, X.; Wang, J.; Meng, F.; Suo, Y.; Han, P. 2015. A novel experimental approach for fracability evaluation in tight-gas reservoirs, Journal of Natural Gas Science \& Engineering 23:239-249. http://dx.doi.org/10.1016/j.jngse.2015.01.039.

4. Shen, Y.;Yang, X,; Zhang, Y. 2017. Production analysis of tight sandstone reservoir in consideration of stresssensitive permeability, The Open Petroleum Engineering Journal 10(1):82-93. https://doi.org/10.2174/1874834101710010082.

5. Xiao, D.; Lu, S.; Yang, J.; Zhang, L.; Li, B. 2017. Classifying multiscale pores and investigating their relationship with porosity and permeability in tight sandstone gas reservoirs, Energy \& Fuels 31 (9): 9188-9200. http://dx.doi.org/10.1021/acs.energyfuels.7b01487.

6. Macbeth, C.; Hajnasser, Y.; Stephen, K.; Gardiner, A. 2015. Exploring the effect of meso-scale shale beds on a reservoir's overall stress sensitivity to seismic waves, Geophysical Prospecting 59(1):90-110. https://doi.org/0.1111/j.1365-2478.2010.00897.x.

7. Tian, X.; Cheng, L.; Zhao, W.; Yan, Y.; He, X.; Guo, Q. 2015. Experimental Study on Permeability Stress Sensitivity in Tight Sandstone Oil Reservoirs, Sains Malaysiana 44(5):719-725. https://doi.org/10.17576/jsm-2015-4405-11.

8. Chen, D.; Pan Z.; Ye, Z. 2015. Dependence of gas shale fracture permeability on effective stress and reservoir pressure: Model match and insights, Fuel 139:383-392. http://dx.doi.org/10.1016/j.fuel.2014.09.018.

9. Dong, J.; Hsu J.; Wu, W.; Shimamoto, T.; Hung, J.; Yeh, E.; Wu, Y.; Sone, H. 2010. Stress-dependence of the permeability and porosity of sandstone and shale from TCDP Hole-A, International Journal of Rock Mechanics \& Mining Sciences 47(7):1141-1157. https://doi.org/10.1016/j.ijrmms.2010.06.019.

10. Moosavi, S. A.; Goshtasbi, K.; Kazemzadeh, E.; Aloki Bakhtiari, H.; Esfahani, M. R.; Vali, J. 2014. Relationship between porosity and permeability with stress using pore volume compressibility characteristic of reservoir rocks, Arabian Journal of Geosciences 7(1):231-239. https://doi.org/10.1007/s12517-012-0760-x.

11. Nazarova, L. A.; Nazarov, L. A.; Epov, M. I.; Eltsov, I. N. 2013. Evolution of geomechanical and electro-hydrodynamic fields in deep well drilling in rocks, Journal of Mining Science 49(5):704-714. https://doi.org/10.1134/s1062739149050031.

12. Ghabezloo, S. 2015. A micromechanical model for the effective compressibility of sandstones, European Journal of Mechanics 51:140-153. https://doi.org/10.1016/j.euromecsol.2014.12.007.

13. Chen, D.; Ye, Z.; Pan, Z.; Zhou, Y.; Zhang, J. 2017. A permeability model for the hydraulic fracture filled with proppant packs under combined effect of compaction and embedment, Journal of Petroleum Science \& Engineering 149:428-435. https://doi.org/10.1016/j.petrol.2016.10.045.

14. Minkoff, S. E.; Stone, C. M.; Bryant, S.; Peszynska, M.; Wheeler, M. F. 2003. Coupled fluid flow and geomechanical deformation modeling. Journal of Petroleum 
Science \& Engineering 38(1):37-56 https://doi.org/10.1016/S0920-4105(03)00021-4.

15. Li, L. C.; Tang, C. A.; Li, G.; Wang, S. Y.; Liang, Z. Z.; Zhang, Y. B. 2012. Numerical simulation of 3D hydraulic fracturing based on an improved flow-stressdamage model and a parallel FEM technique. Rock Mechanics and Rock Engineering 45(5):801-818. https://doi.org/10.1007/s00603-012-0252-z.

16. Wang, R.; Yue, X.; Zhao, R.; Yan, P.; Freeman, D. 2009. Effect of stress sensitivity on displacement efficiency in $\mathrm{CO}_{2}$ flooding for fractured low permeability reservoirs. Petroleum Science 6(3):277-283. https://doi.org/10.1007/s12182-009-0044-6.

17. Gangi, A. F. 1978. Variation of whole and fractured porous rock permeability with confining pressure, International Journal of Rock Mechanics \& Mining Sciences \& Geomechanics Abstracts 15(5):249-257. https://doi.org/10.1016/0148-9062(78)90957-9.

18. Jones, F. O.; Owens, W. W. 1980. A laboratory study of low-permeability gas sands. Journal of Petroleum Technology 32(9):1631-1640. https://doi.org/10.2118/7551-PA.

19. Lei, Q.; Xiong, W.; Yuang, J.; Cui, Y.; Wu, Y. S. 2007 Analysis of stress sensitivity and its influence on oil production from tight reservoirs, Eastern Regional Meeting. https://doi.org/10.2523/111148-MS.

20. Rosalind, A. 2008. Impact of stress sensitive permeability on production data analysis, SPE Unconventional Reservoirs Conference, 10-12 February, Keystone, Colorado, USA. https://doi.org/10.2118/114166-MS.

21. Reber, J. E.; Pec, M. 2018. Comparison of brittle- and viscous creep in quartzites: Implications for semi-brittle flow of rocks. Journal of Structural Geology 113:90-99. https://doi.org/10.1016/j.jsg.2018.05.022.

22. Yang, C.; Daemen, J.; Yin, J. H. 1999. Experimental investigation of creep behavior of salt rock, International Journal of Rock Mechanics \& Mining Sciences 36(2):233-242. https://doi.org/10.1016/S0148-9062(98)00187-9.

23. Cruden, D. M.; Leung, K.; Masoumzadeh, S. 1987. A technique for estimating the complete creep curve of a sub-bituminous coal under uniaxial compression. International Journal of Rock Mechanics \& Mining Sciences
\& Geomechanics Abstracts 24(4):265-269. https://doi.org/10.1016/0148-9062(87)90181-1.

24. Hashiba, K.; Okubo, S.; Fukui, K. 2006. A new testing method for investigating the loading rate dependency of peak and residual rock strength. International Journal of Rock Mechanics and Mining Sciences 43(6):894-904. https://doi.org/10.1016/j.ijrmms.2005.12.005.

Xiangrong Nie, Junbin Chen, Shaomin Yuan

\section{EXPERIMENTAL STUDY ON STRESS SENSIVITY CONSIDERING TIME EFFECT FOR TIGHT GAS RESERVOIRS}

S u m m a r y

Stress sensitivity is a crucial engineering problem in the process of tight gas reservoir development. In this work, the experiments about tight gas reservoirs are performed by confining pressure for a long time to simulate tight gas reservoirs under pressure for a long time during production process. The cores used in the test were from Ordos Basin, which is a typical tight gas reservoir. The results show that the stress sensitivity is increasing with compression time extended. Evaluation method for stress sensitivity about tight reservoirs was established based on time scale. The stress sensitivity for tight gas reservoirs was divided into two feature segments from time scale, which were named instantaneous stress sensitivity and delayed stress sensitivity. The conventional evaluation method for stress sensitivity about tight reservoirs has only considered the instantaneous stress sensitivity, and the delayed stress sensitivity has been ignored. The new method can more accurately simulate the stress sensitivity for tight gas reservoir, which has great guiding significance in rational development for tight gas reservoir.

Key words: tight gas reservoirs, stress sensitivity, effective stress, permeability.

Received April 08, 2018

Accepted December 12, 2018 